\title{
Bigger may not be better either
}

\author{
Daniel P. Raymond, MD
}

\author{
From the Department of Thoracic \& Cardiovascular Surgery, Cleveland Clinic Foundation, Cleveland, Ohio. \\ Disclosures: Author has nothing to disclose with regard to commercial support. \\ Received for publication Nov 28, 2018; accepted for publication Nov 29, 2018. \\ Address for reprints: Daniel P. Raymond, MD, Cleveland Clinic Foundation, 9500 Euclid Ave, J4-1 Cleveland, \\ OH 44195 (E-mail: raymond3 @ ccf.org). \\ J Thorac Cardiovasc Surg 2019;157:1218 \\ $0022-5223 / \$ 36.00$ \\ Copyright $(\subset) 2018$ by The American Association for Thoracic Surgery \\ https://doi.org/10.1016/j.jtcvs.2018.11.119
}

Why do we perform surveillance after surgical therapy for stage I lung cancer? To identify disease recurrence or new disease and intervene to improve survival. This is a fairly obvious concept yet one that remains surprisingly poorly studied despite the large volume of lung cancer treated annually in the world. Subramanian and colleagues ${ }^{1}$ provide much-needed data and insight in this arena with an impressively designed retrospective analysis using the special study mechanism of the Commission on Cancer. This begins with a block of National Cancer Database data augmented by reabstraction to provide specific data points necessary to address the hypothesis. The result is a detailed analysis of more than 2000 patients with stage I lung cancer including longitudinal follow-up over 5 years. As with many other large data studies, we expect bigger to be better.

Typical of any retrospective study, regardless of size, one must be suspicious of bias. In this study, we need to get into the practitioners' heads to determine why they chose a specific interval. Was it a professional guideline? Maybe an institutional protocol? Or maybe based on pathologic and clinical variables? All are potential sources of bias.

Of greatest concern in the present analysis ${ }^{1}$ is the lack of variables, present on the pathology report, which may influence the practitioner's choice of surveillance interval. Although the study provides some of the essential data, including tumor size and histologic type of cancer, there are several important missing variables, including margin distance, histologic subtype, and the presence of lymphovascular invasion (LVI), which may influence surveillance intervals. Micropapillary and papillary subtypes of adenocarcinoma, for instance, are associated with worse overall prognosis $^{2}$ and may influence the selection of surveillance interval. A narrow margin or the presence of LVI may have the same effect. Higgins and colleagues ${ }^{3}$ demonstrated that LVI is associated with a statistically significantly lower freedom from distant metastases (hazard ratio 1.52, $P=.005$ ) and worsening overall survival (hazard ratio

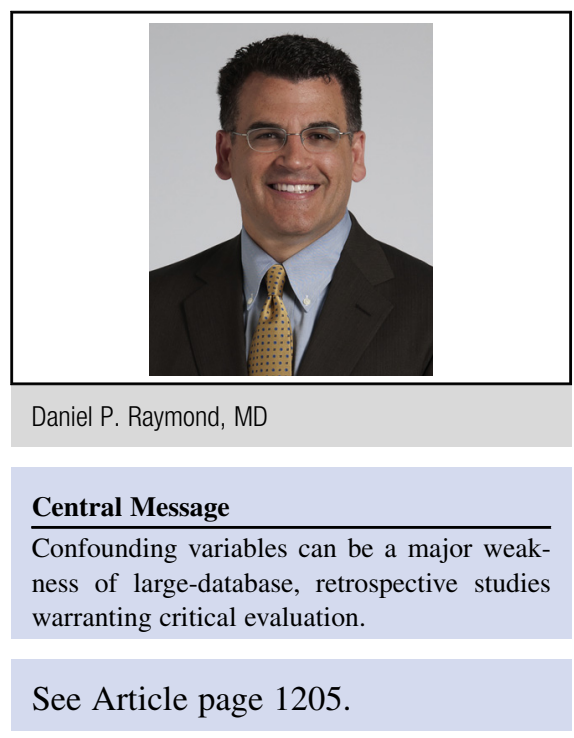

$1.26, P=.006)$. Interestingly, in the present study, the incidence of distant recurrence was also statistically greater in the high-intensity group, thus reinforcing the concern for selection bias.

Despite these challenges, the study by Subramanian and colleagues ${ }^{1}$ remains a valued addition to the sparse literature on surveillance intervals following surgical treatment of early-stage lung cancer. In addition, this study provides valuable insight into the rates of recurrence and rates of development of a metachronous primary lung cancer in a large, modern, multi-institutional patient population. The large population certainly would qualify this study as bigger, similar to all the large database, retrospective studies that inundate the literature. Better, however, would be the next obvious step, a prospective, randomized trial.

\section{References}

1. Subramanian MP, Liu J, Greenberg C, Schumacher J, Chang GJ, McMurry TL, et al. Imaging surveillance for surgically resected stage I non-small cell lung cancer: is more always better? J Thorac Cardiovasc Surg. 2019;157:1205-17.

2. Warth A, Muley T, Meister M, Stenzinger A, Thomas M, Schirmacher P, et al. The novel histologic International Association for the Study of Lung Cancer/American Thoracic Society/European Respiratory Society classification system of lung adenocarcinoma is a stage-independent predictor of survival. J Clin Oncol. 2012;30:1438-46.

3. Higgins KA, Chino JP, Ready N, D'Amico TA, Berry MF, Sporn T, et al. Lymphovascular invasion in non-small-cell lung cancer: implications for staging and adjuvant therapy. J Thorac Oncol. 2012;7:1141-7. 